\title{
Estudo da infecção e morbidade da doença de Chagas no município de João Costa - Parque Nacional Serra da Capivara, Piaú, Brasil
}

\author{
Study of the infection and morbidity of Chagas' disease in municipality \\ of João Costa - National Park Serra da Capivara, Piauí, Brazil
}

\author{
José Borges-Pereira1, José Adail Fonseca de Castro², José Henrique Furtado Campos², José de Souza \\ Nogueira', Patrícia Lago Zauza', Patrícia Marques ${ }^{3}$, Maria Angélica Cardoso ${ }^{3}$, \\ Constança Britto ${ }^{3}$ e Adauto José Gonçalves de Araújo ${ }^{4}$
}

\begin{abstract}
Resumo Com o objetivo de investigar aspectos da infecção e morbidade da doença de Chagas no município de João Costa, Piauí, Brasil, realizamos pesquisa sorológica para detectar lg G anti-T. cruzi em 2.080 moradores através dos testes de imunofluorescência indireta, hemaglutinação indireta e ELISA. Em seguida, 189 pacientes soropositivos e 141 soronegativos foram avaliados pelo exame clínico e eletrocardiograma (ECG), enquanto a parasitemia foi pesquisada em 106 chagásicos pelo xenodiagnóstico indireto e teste da reação polimerásica em cadeia (PCR). A soropositividade total para lg $G$ anti-T.cruzi foi de 9,8\%, com variação de 0,5\% em menores de 10 anos a 39,4\% em maiores de 59 anos, independentemente do sexo. O percentual de ECG alterados foi de $41,3 \%$ entre os chagásicos e de $15,6 \%$ entre os não-chagásicos $(p<0,05)$. A positividade do teste da PCR foi de $74,5 \%$ e a do xenodiagnóstico de $15,1 \%(p<0,05)$. Apesar da elevada prevalência da infecção na população investigada, o baixo valor nos menores de 10 anos pode ser indicador de redução da transmissão por triatomíneos. A alta proporção de participação do componente etiológico exclusivamente chagásico na prevalência da cardiopatia indica a gravidade da doença de Chagas na região estudada.
\end{abstract}

Palavras-chaves: Doença de Chagas. Soroprevalência. Morbidade. João Costa-Piauí. Parque Nacional. Serra da Capivara.

\begin{abstract}
In order to investigate aspects of the infection and morbidity of Chagas' disease in the municipality of João Costa, Piauí State, Brazil, we carried out a serological survey to detect anti-Trypanosoma cruzi antibodies in 2,080 individuals, by indirect immunofluorescence, indirect hemagglutination and ELISA. A total of 189 seropositive and 141 seronegative patients were evaluated by anamnesis, physical exam and electrocardiogram (EKG). The parasitaemia of 106 chagasic patients was evaluated by indirect xenodiagnosis and PCR (polymerase chain reaction). The total seropositivity was $9.8 \%$, with intervals of $0.5 \%$ in patients younger than 10 years old, and $39.4 \%$ among patients older than 59 years old, independently of the sex. The PCR and xenodiagnosis were positive, respectively in $74.5 \%$ and $15.1 \%$ of the seropositive patients $(p<0.05)$. The rate of abnormal EKG was $41.3 \%$ in chagasic and $15.6 \%$ in non-chagasic patients $(p<0.05)$. In spite of the high prevalence of infection in the investigated population, the low rate of seropositivity among children is indicative of a possible decrease of the active transmission mediated by triatomines. The high proportion of the chagasic component on the cardiopathy prevalence is indicative of the high morbidity of Chagas' disease in the studied region.
\end{abstract}

Key-words: Chagas' disease. Seroprevalence. Morbidity. João Costa-Piaui State. National Park. Serra da Capivara.

\footnotetext{
1. Departamento de Medicina Tropical do Instituto Oswaldo Cruz da Fundação Oswaldo Cruz, Rio de Janeiro, RJ. 2. Departamento de Parasitologia da Universidade Federal do Piauí, Teresina, PI. 3. Departamento de Bioquímica e Biologia Molecular do Instituto Oswaldo Cruz da Fundação Oswaldo Cruz, Rio de Janeiro, RJ. 4. Escola Nacional de Saúde Pública da Fundação Oswaldo Cruz, Rio de Janeiro, RJ.

Endereço para correspondência: Dr. José Borges-Pereira. Av. Brasil 4365, Manguinhos, 21040-900 Rio de Janeiro, RJ, Brasil.

Fax: $55212280-3740$

E-mail: borges@ioc.fiocruz.br

Recebido para publicação em 30/5/2001.
} 
Os primeiros relatos sobre a possível existência da doença de Chagas no estado do Piauí foram feitos por Neiva \& Penna ${ }^{23}$ em 1916, mencionando a captura de triatomíneos das espécies Triatoma brasiliensis, Triatoma maculata, Triatoma sordida e Panstrongylus megistus nos municípios de São Raimundo Nonato, Parnaguá e Correntes, com alguns exemplares infectados por Trypanosoma cruzi, assim como a presença de indivíduos com queixas de entalo e vexame, manifestações sugestivas de megaesôfago e cardiopatia.

Seis décadas depois, em 1975, Figueiredo et a/19 confirmaram o diagnóstico dos primeiros casos autóctones da doença de Chagas com manifestações cardíacas e digestivas provenientes de Oeiras, Castello e Bom Jesus do Gurguéia. Nessa mesma ocasião, Correia-Lima et a/ ${ }^{13}$ observaram a variação da soroprevalência da infecção chagásica humana de $0,88 \%$ a $11 \%$ entre moradores de 24 municípios estudados. Em 1976, Correia-Lima ${ }^{12}$ em estudo realizado em Oeiras, envolvendo as localidades de Colônia e Oitis, encontrou: T. brasiliensis como o único triatomíneo capturado nos domicílios com um índice de infecção natural de 4,9\%; soropositividade para infecção chagásica em $12,1 \%$ da população investigada com predomínio no grupo de mulheres; xenopositividade de $19 \%$ entre chagásicos crônicos e um excesso de eletrocardiogramas alterados de $18 \%$ entre os chagásicos em comparação com os não-chagásicos.

Em 1984, Camargo et a $\beta$, a partir dos dados do inquérito sorológico nacional realizado no período 1975 1980 , estimaram em $4 \%$ a prevalência da infecção chagásica humana para todo o estado do Piauí, enquanto Macedo et $a^{22}$, com base no inquérito eletrocardiográfico nacional, encontraram prevalência de ECG alterado em $45 \%$ dos chagásicos e em $28,5 \%$ dos não-chagásicos. Bento et $a^{\beta}$, no período 1984-1985, em localidades dos municípios de Castelo do Piauí e Pedro II, identificaram $21,7 \%$ de soropositivos pelo teste de imunofluorescência indireta entre as 566 pessoas examinadas, destacando a positividade acima de $10 \%$ em menores de 10 anos e a captura de T. brasiliensis no intradomicílio com infecção por $T$. cruzi de $7,5 \%$, T. pseudomaculata no peridomicílio sem infecção e
Rhodnius nasutus no ambiente silvestre com 1,3\% de infecção.

Em 1995, Alves Filho1, em novo estudo seccional em Oeiras, relatou a captura de $T$. brasiliensis e $T$. sordida, queda da soroprevalência para $5,96 \%$ entre os moradores e a presença de megaesôfago em $26 \%$ dos chagásicos com disfagia. Nessa mesma ocasião, Junqueira et $a^{R 1}$ identificaram $60 \%$ de positividade do teste da PCR (polymerase chain reaction), 34\% de xenodiagnósticos indiretos positivos e $26 \%$ de hemoculturas positivas entre os chagásicos crônicos examinados. Ainda como produto desse estudo, Castro ${ }^{11}$ caracterizou as cepas de T. cruzi isoladas de chagásicos crônicos como sendo predominantemente de média e baixa virulência em camundongos, sem diferenças significativas em relação aos perfis de proteínas vistos pela técnica de Western blot, enquanto Fernandes et a/18 identificaram, através da amplificação da região intergênica do gene de mini-exon, a presença da linhagem 1 entre os isolados de pacientes chagásicos crônicos e as linhagens 1 e 2 entre os isolados de $T$. brasiliensis capturados nas unidades domiciliares do mesmo município.

Em 1998, Silveira \& Vinhaes ${ }^{27}$ assinalaram positividade sorológica em 2 (0,04\%) dos 4.989 escolares de 7 a 14 anos procedentes de 14 municípios do estado do Piauí, examinados no período 1996/1997. Referiram também que o $T$. brasiliensis representou $62 \%$ dos triatomíneos capturados em todo o Estado no período 1993-1997, enquanto o T.pseudomaculata e T. infestans representaram, respectivamente, $30 \%$ e $0,17 \%$.

Com base nesses estudos podemos considerar a prevalência da infecção chagásica humana no Estado em queda, apesar da captura sistemática de expressivo número de $T$. brasiliensis ${ }^{26}{ }^{27}$. Entretanto, as características da morbidade têm sido referenciadas a partir dos estudos realizados exclusivamente na região de Oeiras, o que não garante uma análise de possíveis diferenças na doença dentro do Estado. Essa questão se constituiu no principal determinante do presente trabalho, no qual investigamos o comportamento da doença de Chagas no município de João Costa, criado em 1997, sem referência de estudo anterior.

\section{MATERIAL E MÉTODOS}

Área de estudo. O município de João Costa fica situado na região sudeste do estado do Piauí, na área do Parque Nacional Serra da Capivara. Limita-se com os municípios de Dom Inocêncio, Brejo do Piauí, Ribeira do Piauí, Capitão Gervásio de Oliveira, São Raimundo Nonato, São João do Piauí e Coronel José Dias (Figura 1). Foi criado em 1997, com o desmembramento do município de São João do Piauí. Possui uma área de $1.873 \mathrm{Km}^{2}$ e uma população estimada em 2.740 habitantes. Caracteriza-se por vegetação do tipo Caatinga, temperatura média anual entre $24^{\circ} \mathrm{C}$ e $26^{\circ} \mathrm{C}$, com máxima de $42^{\circ} \mathrm{C}$ e mínima de $8^{\circ} \mathrm{C}$.
Estudo sorológico. O objetivo inicial era realizar a triagem sorológica de toda a população maior de um ano de idade $(n=2.631$ pessoas); todavia, somente foram obtidas amostras de sangue em papel de filtro de 2.080 pessoas, sendo $432(91 \%)$ das 475 residentes na zona urbana e 1.648 (76\%) das 2.156 (76\%) residentes da zona rural. As demais pessoas não foram examinadas por estarem ausentes na ocasião da investigação, ou por se recusarem a participar da pesquisa. Entre as 2.080 pessoas participantes da triagem sorológica, 1.001 eram do sexo feminino e 1.079 do sexo masculino (Tabela 1) com idades de 1 a 89 


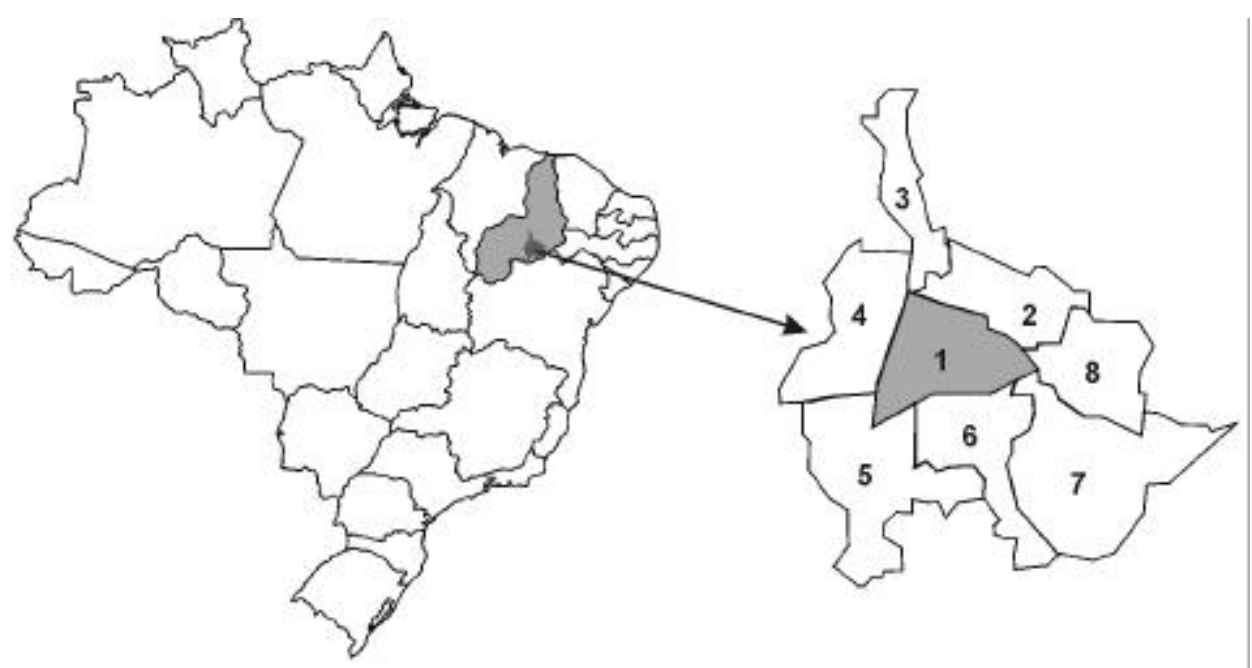

Figura 1 - Localização da área de estudo (1: João Costa) no Estado do Piauí, Brasil e dos municípios limítrofes (2: São João do Piauí, 3: Ribeira do Piaul, 4: Brejo do Piauí, 5: São Raimundo Nonato, 6: Coronel José Dias, 7: Dom Inocêncio, 8: Capitão Gervásio de Oliveira).

\begin{tabular}{|c|c|c|c|c|c|c|c|c|c|}
\hline \multirow{2}{*}{$\begin{array}{l}\text { Faixa etária } \\
\text { (anos) } \\
1-9\end{array}$} & \multicolumn{3}{|c|}{ Mulheres } & \multicolumn{3}{|c|}{ Homens } & \multicolumn{3}{|c|}{ Total } \\
\hline & $\begin{array}{c}\text { exam } \\
189\end{array}$ & $\begin{array}{c}\text { sorop } \\
1\end{array}$ & $\begin{array}{r}\% \\
0,5\end{array}$ & $\begin{array}{c}\text { exam } \\
192\end{array}$ & $\frac{\text { sorop }}{1}$ & $\begin{array}{l}\% \\
0,5\end{array}$ & $\begin{array}{c}\text { exams } \\
381\end{array}$ & $\begin{array}{c}\text { sorop } \\
2\end{array}$ & $\begin{array}{c}\% \\
0,5\end{array}$ \\
\hline $10-19$ & 264 & 2 & 0,8 & 327 & 4 & 1,2 & 591 & 6 & 1,0 \\
\hline $20-29$ & 149 & 2 & 1,3 & 163 & 4 & 2,4 & 312 & 6 & 1,9 \\
\hline $30-39$ & 131 & 9 & 6,9 & 134 & 5 & 3,7 & 265 & 14 & 5,3 \\
\hline $40-49$ & 86 & 22 & 25,6 & 103 & 25 & 24,4 & 189 & 47 & 24,9 \\
\hline 50-59 & 81 & 29 & 35,8 & 73 & 27 & 37,0 & 154 & 56 & 36,4 \\
\hline$\geq 60$ & 101 & 45 & 44,5 & 87 & 29 & 34,3 & 188 & 74 & 39,4 \\
\hline Total & 1.001 & 110 & 11,0 & 1.079 & 95 & 8,8 & 2.080 & 205 & 9,8 \\
\hline
\end{tabular}

exam = examinados; sorop = soropositivos pelos testes de IFI, HAI e/ou ELISA

anos. As amostras de sangue em papel de filtro foram submetidas ao teste de imunofluorescência indireta $(\mathrm{IFI})^{8}$, na sede do município. Para a confirmação do resultado sorológico da triagem, assim como a realização de exames clínico e eletrocardiograma, foram convidadas todas as 216 pessoas com a IFI em eluato de sangue positiva e igual número de pessoas, pareadas por idade e sexo, com IFI negativa. $\mathrm{Na}$ confirmação sorológica foram empregados os testes de IFI (Bio-Manguinhos), hemaglutinação indireta (Biolab) e ELISA recombinante CRA+FRA (Bio-Manguinhos). A pesquisa de anticorpos anti-T.cruzi no soro foi considerada positiva diante da reação em diluições $=$ 1:40 nos testes de IFI e hemaglutinação indireta e da densidade óptica 1.2 vezes maior do que o cut-off estabelecido pelos controles. A soroprevalência da infecção chagásica foi definida a partir do resultado confirmatório de dois ou mais testes aplicados. A participação das pessoas em todas as etapas do estudo se deu de modo voluntário, após esclarecimento acerca da investigação, benefícios e riscos.
Exame clínico e eletrocardiográfico. Apesar dos 205 pares de pessoas convidadas para estes exames, somente 189 soropositivos ( 105 mulheres e 84 homens com idades de 14 a 83 anos, média $=54 \pm 15,6$ anos) e 141 soronegativos (83 mulheres e 58 homens com idades de 14 a 84 anos, média $=52 \pm 14,8$ anos) compareceram e as demais se recusaram a participar do estudo ou estavam ausentes na ocasião dessa etapa. A avaliação clínica consistiu de anamnese e exame físico dirigidos aos aparelhos cardiovascular e digestivo e realizados por pelo menos dois examinadores. A pressão arterial foi tomada após repouso de 15 minutos, considerando-se a presença de hipertensão para os valores maiores de $95 \mathrm{mmHg}$ (mínima) e $160 \mathrm{mmHg}$ (máxima). O eletrocardiograma foi obtido em repouso com o registro de, no mínimo, três complexos nas doze derivações clássicas mais D2 longo, no caso de arritmia. A leitura foi realizada por dois observadores considerando-se normais as freqüências de 60 a $120 \mathrm{bpm}$ e a arritmia sinusal. 
Xenodiagnóstico (XD) e PCR (polymerase chain reaction). Após a confirmação da soropositividade, 106 pacientes, convidados aleatoriamente, compareceram para coleta de $10 \mathrm{ml}$ de sangue venoso destinadas ao xenodiagnóstico indireto e o teste da PCR. No XD foram utilizadas quatro caixas de madeira apropriadas para o exame por paciente. Cada caixa com 10 ninfas no III ou IV estádios de $T$. brasiliensis (duas caixas/xeno) e T. infestans (duas caixas/xeno). A cada conjunto de duas caixas foi oferecido um preservativo contendo $5 \mathrm{ml}$ de sangue heparinizado para o repasto das ninfas no tempo de uma hora na temperatura ambiente. O exame das fezes ou do triturado do tubo digestivo de cada ninfa, entre lâmina e lamínula, foi feito em média 45 dias após o repasto, através da observação microscópica.

Para o teste da PCR a partir da punção venosa destinada à coleta de sangue para o $\mathrm{XD}$, foi obtido 0 volume de $10 \mathrm{ml}$ de sangue em tubo não heparinizado e imediatamente misturado a $10 \mathrm{ml}$ de solução de Guanidina-HCl 6 M e EDTA $0.2 \mathrm{M}$ (solução de lise). Os tubos contendo os lisados de sangue foram mantidos à temperatura ambiente por no máximo 10 dias, em seguida encaminhados ao Departamento de Bioquímica e Biologia Molecular para processamento dirigido à detecção de k-DNA de $T$. cruzi através da técnica para a reação da PCR, conforme procedimentos adotados por Britto et $\mathrm{a}^{\mathrm{C}}$ e Wincker et $\mathrm{a}^{\mathrm{R}}$ empregando os primers 5'-AAATAATGTACGGG(T/G)GAGATGCATGA-3' e 5'-GGTTGCATTGGGTTGGTGTAATATA-3' que amplificam o fragmento de 330 pares de bases contendo as regiões hipervariáveis dos minicírculos do DNA do cinetoplasto (k-DNA) do parasita.

Estatística. Os dados foram submetidos à análise estatística através do pacote contido no programa EPIINFO.6, considerando nível de significância de 5\% para a aceitação da hipótese nula, aplicando testes do quiquadrado e exato de Fischer. Para estimar a proporção de participação do componente etiológico exclusivamente chagásico na prevalência da cardiopatia, empregamos o método de Sheps ${ }^{25}$, resumido na equação: $\mathrm{PC}=(\mathrm{XC} / \mathrm{NC})-(\mathrm{XO} / \mathrm{NO}) \times(\mathrm{NO} /$ NO-XO) na qual PC $=$ proporção de cardiopatia de etiologia chagásica, $\mathrm{XC}=$ número de chagásicos com ECG alterados; $N C=$ total de chagásicos examinados, $\mathrm{XO}=$ número de não-chagásicos com ECG alterados e $\mathrm{NO}=$ total de não-chagásicos examinados.

\section{RESULTADOS}

Soropositividade. Entre os 2.080 moradores investigados na triagem sorológica, 216 apresentaram o teste de IFI positivo em eluato de sangue. Desses 216 moradores, $205(94,8 \%)$ tiveram a positividade confirmada: 198 por IFI, HAI e ELISA e sete por IFI e ELISA em soros. Com estes resultados, a soropositividade total da infecção chagásica foi estimada em $9,8 \%$, sem diferença significativa em relação ao sexo $(X=2.79 ; p=0,094)$ e freqüências crescentes com o aumento da faixa etária, ressaltando-se os baixos valores nos menores de 30 anos (Tabela 1).

Exame clínico. A sintomatologia de natureza cardiovascular foi revelada em $114(60,3 \%)$ pacientes soropositivos e $51(36,2 \%)$ soronegativos $(R R=1,65$; $p=0,00001$ ), enquanto as manifestações de natureza digestiva foram reveladas em $63(33,3 \%)$ soropositivos e $29(20,6 \%)$ soronegativos ( $R R=1,65 ; p=0,01$ ). Dispnéia, palpitações em repouso, arritmia à ausculta e desdobramento da segunda bulha cardíaca foram a manifestações cardiovasculares com freqüências significativamente maiores entre os soropositivos em comparação com os soronegativos, enquanto que entre as manifestações digestivas predominaram a disfagia e a obstipação intestinal (Tabela 2); ressaltando-se que dois pacientes soropositivos foram submetidos ao tratamento cirúrgico, um por causa de megacólon e o outro por causa de megaesôfago, ambos com ECG normal até o momento do presente exame.

Eletrocardiografia. O ECG foi considerado anormal em $78(41,3 \%)$ soropositivos e $22(15,6 \%)$ soronegativos $(R R=2,65 ; p=0,0000005)$. Com esses dados, estimamos a participação do componente exclusivamente chagásico na prevalência de cardiopatia em $30,4 \%$ dos pacientes (Figura 2). A diferença nas freqüências de ECG anormal não foi significativa em relação ao sexo dos soropositivos e dos soronegativos, enquanto que em função da idade, as freqüências aumentaram, de modo significativo, diretamente com as faixas etárias, tanto em soropositivos como em soronegativos (Tabela 3). O bloqueio completo do ramo direito, hemibloqueio anterior esquerdo, extra-sístoles ventriculares complexas e alteração primária da repolarização ventricular foram as alterações eletrocardiográficas com prevalências significativamente maiores entre os soropositivos (Tabela 4).

Xenodiagnóstico e PCR. Dos 106 pacientes soropositivos submetidos a ambos os exames pareados, $79(74,5 \%)$ apresentaram positividade pela técnica da PCR e $16(15,1 \%)$ apresentaram XD positivo $\left(X^{2}=75,34\right.$; $p<0,0000001)$. A PCR positiva foi diagnosticada em todos os pacientes com XD positivo e em $63(70 \%)$ dos 90 pacientes com XD negativo. $A$ análise das freqüências de positividade da PCR e do XD não mostrou diferenças significativas em relação aos resultados do exame clínico, eletrocardiograma e sexo dos pacientes. Dos 16 XD positivos, $8(12,9 \%)$ foram identificados no grupo de 62 pacientes com idade inferior a 59 anos e $8(18,2 \%)$ foram identificados no grupo de 44 pacientes com 60 ou mais anos $\left(X^{2}=0,56\right.$; $p=0,454)$. Do total de 3.565 ninfas examinadas, 42 $(1,2 \%)$ estavam positivas para T. cruzi, sendo $22(1,2 \%)$ entre as 1.876 de $T$. infestans e $20(1,2 \%)$ entre as 1.689 de $T$. brasiliensis $\left(X^{2}=0,00 ; p=0,974\right)$. 
Tabela 2 - Freqüências das manifestações clínicas em soropositivos e soronegativos para infecção chagásica. João Costa, Piauí, Brasil, 2000

\begin{tabular}{|c|c|c|c|c|c|}
\hline \multirow[b]{2}{*}{ Manifestações clínicas } & \multicolumn{2}{|c|}{ Soropositivos $(n=189)$} & \multicolumn{2}{|c|}{ Soronegativos $(n=141)$} & \multirow[b]{2}{*}{$P=$} \\
\hline & $\mathrm{n}^{\circ}$ & $\%$ & $\mathrm{n}^{\circ}$ & $\%$ & \\
\hline \multicolumn{6}{|l|}{ Cardiovasculares } \\
\hline palpitações em repouso & 72 & 38,1 & 30 & 21,3 & 0,001 \\
\hline dispnéia aos esforços & 47 & 24,9 & 21 & 14,2 & 0,026 \\
\hline desdobramento de B2 & 19 & 10,1 & 1 & 0,7 & 0,0004 \\
\hline arritmia à ausculta & 18 & 9,5 & 3 & 2,1 & 0,006 \\
\hline dor precordial em repouso & 28 & 14,8 & 14 & 9,9 & 0,187 \\
\hline hipertensão arterial & 26 & 13,8 & 19 & 13,5 & 0,941 \\
\hline perda da consciência & 22 & 11,6 & 11 & 7,8 & 0,250 \\
\hline sopro sistólico & 5 & 2,6 & 1 & 0,7 & 0,244 \\
\hline \multicolumn{6}{|l|}{ Digestivas } \\
\hline disfagia & 37 & 19,6 & 9 & 6,4 & 0,0006 \\
\hline obstipação intestinal de 5-10 dias & 12 & 6,3 & 1 & 0,7 & 0,009 \\
\hline obstipação intestinal > 10 dias & 7 & 3,7 & 1 & 0,7 & 0,144 \\
\hline uso obrigatório de laxativo & 8 & 4,2 & 0 & - & - \\
\hline pirose & 36 & 19,0 & 24 & 17,0 & 0,636 \\
\hline regurgitação ativa & 10 & 5,3 & 2 & 1,4 & 0,063 \\
\hline regurgitação passiva & 9 & 4,8 & 2 & 1,4 & 0,124 \\
\hline uso ocasional de laxativo & 8 & 4,2 & 3 & 2,1 & 0,364 \\
\hline
\end{tabular}

Teste qui-quadrado e exato de Fischer

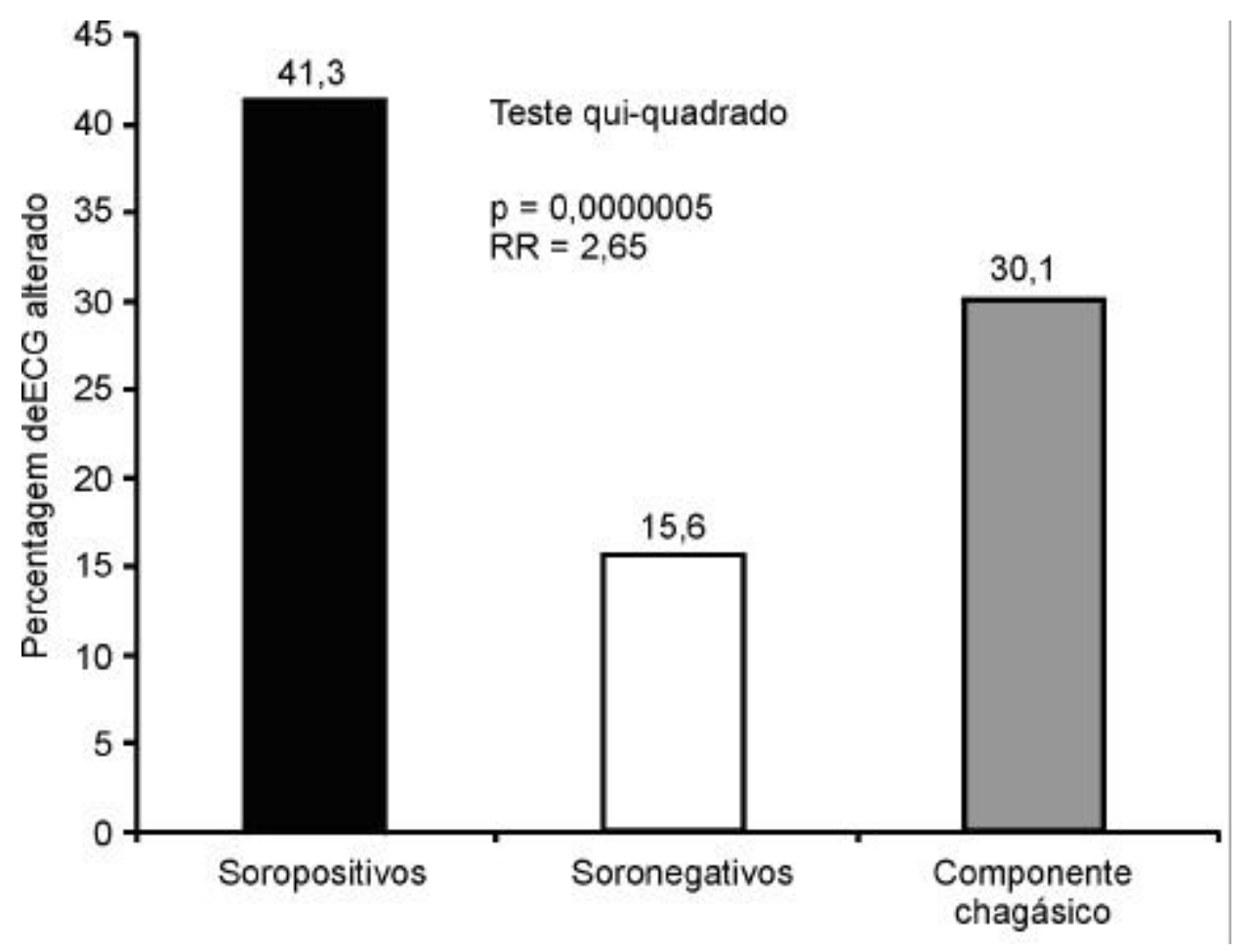

Figura 2 - Prevalência de ECG alterado em 189 soropositivos e 141 soronegativos e o componente etiológico exclusivamente chagásico, João Costa, Piauí, Brasil, 2000. 
Tabela 3 - Freqüências de ECG alterados em soropositivos e soronegativos para infecção chagásica de acordo com a faixa etária e sexo. João Costa, Piauí, Brasil, 2000.

\begin{tabular}{|c|c|c|c|c|c|c|c|}
\hline \multirow[b]{2}{*}{ Variáveis } & \multicolumn{3}{|c|}{ Soropositivos(n=189) } & \multicolumn{3}{|c|}{ Soronegativos $(\mathrm{n}=141)$} & \multirow[b]{2}{*}{$P=$} \\
\hline & examinados & ECGa & $\%$ & examinados & ECGa & $\%$ & \\
\hline \multicolumn{8}{|c|}{ Faixa etária (anos) } \\
\hline $14-29$ & 12 & 1 & 8,3 & 12 & 0 & - & - \\
\hline $30-39$ & 12 & 1 & 8,3 & 12 & 1 & 8,3 & 1,000 \\
\hline $40-49$ & 42 & 13 & 30,9 & 45 & 5 & 11,1 & 0,022 \\
\hline $50-59$ & 55 & 26 & 47,3 & 37 & 5 & 13,5 & 0,0007 \\
\hline$\geq 60$ & 68 & 37 & 54,4 & 36 & 9 & 25,0 & 0,004 \\
\hline \multicolumn{8}{|l|}{ Sexo } \\
\hline feminino & 105 & 39 & 37,1 & 83 & 13 & 15,7 & 0,001 \\
\hline masculino & 84 & 39 & 46,4 & 58 & 9 & 15,5 & 0,0001 \\
\hline Total & 189 & 78 & 41,3 & 141 & 22 & 15,6 & 0,0000005 \\
\hline
\end{tabular}

ECGa = eletrocardiograma alterado; teste qui-quadrado e exato de Fisher

Tabela 4 - Freqüências das alterações eletrocardiográficas em soropositivos e soronegativos, João Costa, Piauí, Brasil, 2000.

\begin{tabular}{|c|c|c|c|c|c|}
\hline \multirow[b]{2}{*}{ Alterações eletrocardiográficas } & \multicolumn{2}{|c|}{ Soropositivos $(n=189)$} & \multicolumn{2}{|c|}{ Soronegativos $(n=141)$} & \multirow[b]{2}{*}{$P=$} \\
\hline & $\mathrm{n}^{\circ}$ & $\%$ & $\mathrm{n}^{\circ}$ & $\%$ & \\
\hline Bloqueio completo do ramo direito & 29 & 15,3 & 3 & 2,1 & 0,00005 \\
\hline Hemibloqueio anterior esquerdo & 26 & 13,8 & 4 & 2,8 & 0,0006 \\
\hline APRV & 21 & 11,1 & 7 & 5,0 & 0,047 \\
\hline EV complexas** & 13 & 6,9 & 0 & - & - \\
\hline EV isolada $(<3 / \mathrm{min})$ & 11 & 5,8 & 1 & 0,7 & 0,014 \\
\hline EV freqüente monofocal ( $\geq 3 / \mathrm{min})$ & 8 & 4,2 & 2 & 1,4 & 0,198 \\
\hline Bloqueio AV I & 5 & 2,6 & 2 & 1,4 & 0,703 \\
\hline Bloqueio do ramo direito I & 3 & 1,6 & 0 & - & - \\
\hline Sobrecarga atrial esquerda & 3 & 1,6 & 1 & 0,7 & 0,638 \\
\hline Bradicardia sinusal (<60 bpm) & 2 & 1,1 & 0 & - & - \\
\hline Zona eletricamente inativa & 2 & 1,1 & 0 & - & - \\
\hline Baixa voltagem de QRS & 1 & 0,5 & 2 & 1,4 & 0,577 \\
\hline Bloqueio AV II & 1 & 0,5 & 0 & - & - \\
\hline Extra-sístoles supraventriculares & 1 & 0,5 & 0 & - & - \\
\hline Fibrilação atrial & 1 & 0,5 & 0 & - & - \\
\hline Sobrecarga ventricular esquerda & 1 & 0,5 & 1 & 0,7 & 1,000 \\
\hline Bloqueio completo do ramo esquerdo & 0 & - & 1 & 0,7 & - \\
\hline
\end{tabular}

Teste qui-quadrado e exato de Fischer

APRV = alteração primária da repolarização ventricular

${ }^{* *}$ geminadas, polifocal e em salvas

\section{DISCUSSÃO}

Este estudo foi realizado em João Costa como parte do projeto desenvolvido pela Fundação Museu do Homem Americano (FUNDHAM) sobre o diagnóstico da saúde nas populações que habitam áreas do Parque Nacional Serra da Capivara. Dentro das características descritivas do presente trabalho podemos considerar que os resultados, no geral, configuram a prevalência da infecção chagásica humana no município de João Costa como alta, duas vezes maior do que os valores estimados há 20 anos para o estado do Piauí e o Brasil ${ }^{9}$.

Apesar da elevada soroprevalência da infecção chagásica na área estudada, o seu baixo valor em menores de 20 anos mostra similaridade com o perfil observado no inquérito sorológico nacional entre escolares de 7 a 14 anos, tanto do Estado do Piauí como de outros Estados do Brasil, confirmado em estudos pontuais realizados em Berilo², Pains e Iguatama ${ }^{17} \mathrm{em}$ Minas Gerais e distrito sanitário de Rio Verde no Mato Grosso do Sul 6 , configurando a eficácia das medidas de controle dirigidas para a transmissão vetorial nessas áreas. Entretanto, Ramos $\mathrm{Jr}^{24}$, em estudo realizado em João Costa, no período 1999-2000, chama a atenção para a persistência de condições favoráveis à manutenção da endemia chagásica ao relatar: ausência de triagem sorológica no banco de sangue de referência do município e descontinuidade da ação de combate direto aos triatomíneos com a captura de 1.826 exemplares de triatomíneos $(80 \%$ de T. brasiliensis, $18 \%$ de T. pseudomaculata e $2 \%$ de $T$. sordida) predominantemente no interior dos 
481 domicílios investigados; destacando também a infecção natural por T. cruzi em $1 \%$ dos exemplares de T. brasiliensis e a maioria das habitações apropriadas à colonização por esses vetores.

A diferença não significativa na prevalência da infecção chagásica em relação ao sexo dos moradores de João Costa é semelhante aos achados de estudos recentes realizados em áreas como Oeiras, PI, Berilo, Pains e Iguatama, MG, consideradas livres da infecção via vetorial e que em estudos anteriores foi evidenciada maior prevalência entre as mulheres. Essa queda na prevalência da infecção entre as mulheres, associada com a ausência ou redução da transmissão vetorial intradomiciliar, reforça a idéia de que a maior prevalência encontrada anteriormente poderia ser dependente do hábito de permanecer mais tempo no interior do domicílio do que dependente de maior sensibilidade à infecção pelo T. cruzi.

A positividade dos xenodiagnósticos entre os pacientes soropositivos de João Costa não difere do resultado encontrado por Correia-Lima em Oieras, $\mathrm{PI}^{12}$ empregando xenodiagnóstico direto, porém, é significativamente menor do que a positividade encontrada por Junqueira et $a^{R^{1}}$ também em Oeiras, PI, quinze anos depois com a mesma metodologia. Essas diferenças nos resultados podem ser atribuídas principalmente às características das populações estudadas e às variações na metodologia de aplicação do xenodiagnóstico.

Independentemente das modificações na metodologia do xenodiagnóstico, os dados da literatura nos mostram uma associação direta entre percentuais de positividade do xenodiagnóstico e os indicadores de morbidade da doença de Chagas crônica. Em áreas com elevados índices das formas cardíaca e digestiva como Virgem da Lapa ${ }^{4}$, Berilo, Pains, Iguatama, Minas Gerais e Oeiras no Piauí ${ }^{14}$, a positividade do xenodiagnóstico direto tem ultrapassado $20 \%$, enquanto em áreas com baixos índices dessas formas clínicas, como Sertão da Paraíba ${ }^{5}$, Rio Verde, $\mathrm{MS}^{6}$, a positividade oscila em torno de 15\%. Não há explicações consistentes para essa associação. Estudos evolutivos realizados em Virgem da Lapa, MG ${ }^{4}$ e Mambaí, GO ${ }^{10}$ não encontraram correlação entre a parasitemia identificada pelo xenodiagnóstico e a progressão da doença, resultados esses que não permitem afastar a influência do parasita no processo evolutivo.

A positividade da técnica da PCR em 74,5\% dos chagásicos crônicos de João Costa comparada com os $60 \%$ encontrados em Oeiras, $\mathrm{Pl}^{21}$, área com os mesmos índices de cardiopatia e comprometimento do aparelho digestivo, não foi estatisticamente significativa. Mas se mostrou inferior aos 95\% encontrados em Virgem da
Lapa, MG ${ }^{27}$, área com elevado índice de cardiopatia; e superior aos $44 \%$ encontrados no Sertão da Paraíba ${ }^{7}$, área com baixo índice de cardiopatia e de megaesôfago, indicando variação regional nos níveis da parasitemia na fase crônica de acordo com área estudada, do mesmo modo que o xenodiagnóstico.

O quadro clínico geral da doença de Chagas observado em João Costa pode ser caracterizado pela presença de cardiopatia, megaesôfago e megacólon, semelhante ao quadro observado tanto em Oeiras, PI como em outras áreas endêmicas do Brasil ${ }^{6} 1014$, com significativa predominância de dispnéia aos esforços, palpitações, arritmias à ausculta, desdobramento da segunda bulha cardíaca, disfagia e obstipação intestinal com duração de 10 ou mais dias.

A prevalência de cardiopatia chagásica crônica, estimada pelo método das proporções de Sheps, foi de $30,4 \%$ em João Costa, não diferindo de modo significativo da estimativa de $23 \%$ feita para Oeiras ${ }^{12}$ e todo o estado do Piauí22 assim como não difere da estimativa de $30 \%$ feita para Virgem da Lapa ${ }^{4}$ e Berilo ${ }^{2}$ em Minas Gerais, áreas classificadas por Coura et al ${ }^{16}$ como de alta morbidade. Por outro lado, é significativamente maior do que as estimativas de $15 \%$ e $19 \%$ feitas, respectivamente, para o Sertão da Paraíba ${ }^{5}$ e autóctones do distrito sanitário de Rio Verde, Mato Grosso do Sul 6 , áreas classificadas como de baixa morbidade ${ }^{16}$. Essas diferenças regionais na prevalência da cardiopatia chagásica crônica estão sempre associadas com diferenças no quadro de alterações eletrocardiográficas. Assim é que, entre os pacientes das áreas com prevalências similares à de João Costa, observam-se as maiores freqüências de bloqueio completo do ramo direito, hemibloqueio anterior esquerdo, extra-sístoles complexas e distúrbios da condução átrio-ventricular isoladamente ou associadas, representando maior gravidade.

Tomando como base a participação do componente etiológico chagásico nas prevalências da cardiopatia em diversas áreas endêmicas do Brasil, Coura et $a^{16}$ consideram Oeiras, PI como área de alta morbidade da doença de Chagas. Podemos considerar João Costa no mesmo grupo de Oeiras, na medida em que os resultados são semelhantes. Esse comportamento homogêneo na morbidade entre os pacientes naturais e moradores dessas áreas não difere da observação feita em piauienses residentes por longo tempo em cidades como São Paulo ${ }^{20}$ e Rio de Janeiro ${ }^{15}$. Com isso, acreditamos ser pouco provável que outras áreas do Estado apresentem perfil clínico que defina diferenças regionais dentro do Piauí.

\section{AGRADECIMENTOS}

Os autores agradecem aos funcionários da Fundação Museu do Homem Americano (FUNDHAM) e da Secretaria Municipal de Saúde de João Costa pela colaboração em todas as etapas do trabalho de campo. 


\section{REFERÊNCIAS BIBLIOGRÁFICAS}

1. Alves Filho Fl. Morbidade da doença de Chagas em áreas endêmicas dos municípios de Oeiras e Colônia do Piauí. Dissertação de Mestrado, Instituto Oswaldo Cruz, FIOCRUZ, Rio de Janeiro, RJ, 1995.

2. Araújo RM. Morbidade da doença de Chagas no município de Berilo, Minas Gerais. Estudos seccional e evolutivo de 10 anos (1987-1997). Tese de doutorado. Instituto Oswaldo Cruz, FIOCRUZ, Rio de Janeiro, RJ, 1998.

3. Bento DNC, Freitas M, Pinto AS. Epidemiologia da doença de Chagas nos municípios de Castelo do Piauí e Pedro II, Estado do Piauí, Brasil. Revista da Sociedade Brasileira de Medicina Tropical 22:73-79, 1989.

4. Borges-Pereira J. Doença de Chagas humana: Estudo da infecção crônica, morbidade e mortalidade em Virgem da Lapa, MG, Brasil (1976-1996). Tese de doutorado, Instituto Oswaldo Cruz, FIOCRUZ, Rio de Janeiro. 1997.

5. Borges-Pereira J, Coura JR. Morbidade da doença de Chagas em populações urbanas do Sertão da Paraíba. Revista da Sociedade Brasileira de Medicina Tropical 20: 101-107, 1987.

6. Borges-Pereira J, Zauza PL, Galhardo MC, Nogueira JS, Pereira G, Cunha RV. Doença de Chagas no distrito sanitário de Rio Verde, Mato Grosso do Sul. II - Prevalência de miocardiopatia de etiologia exclusivamente chagásica. Revista da Sociedade Brasileira de Medicina Tropical 33 (supl I): 383-384, 2000.

7. Britto C, Cardoso MA, Ravel C, Santoro A, Borges-Pereira J, Coura JR, Morel CM, Wincker P. Trypanosoma cruzi: parasite detection and strain discrimination in chronic chagasic patients from northeastern Brazil using amplification of kinetoplast DNA and nonradioactive hybridization. Experimental Parasitology 81: 462-471, 1995.

8. Camargo ME. Fluorescent antibody test for the serodiagnosis of American trypanosomiasis. Technical modification employing preserved culture forms of Trypanosoma cruzi in a slide test. Revista do Instituto de Medicina Tropical de São Paulo 8: 227234, 1966.

9. Camargo ME, Silva JR, Castilho EA, Silveira AC. Inquérito sorológico da prevalência da infecção chagásica no Brasil, 19751980. Revista do Instituto de Medicina Tropical de São Paulo 26 192-204, 1984.

10. Castro CN. Influência da parasitemia no quadro clínico da doença de Chagas. Revista de Patologia Tropical 9:73-136, 1980.

11. Castro JAF. Trypanosoma cruzi e morbidade da doença de Chagas em duas áreas endêmicas no nordeste do Brasil. Tese de doutorado, Instituto Oswaldo Cruz, FIOCRUZ, Rio de Janeiro, RJ, 1997.

12. Correia-Lima FG. Doença de Chagas no município de Oeiras Piauí - estudo seccional nas localidades de Colônia e Oitis. Dissertação de Mestrado, Faculdade de Medicina da Universidade Federal do Rio de Janeiro, RJ, 1976.

13. Correia-Lima FG, Figueiredo PZ, Portella-Nunes JN. Prevalência da infecção chagásica na população humana determinada pelo teste de imunofluorescência indireta em 24 municípios do Piauí. Revista da Sociedade Brasileira de Medicina Tropical 10: 17-25, 1976.

14. Coura JR, Abreu LL, Dubois LEG, Correia-Lima FG, Arruda Jr ER, Willcox HPF, Anunziato N, Petana W. Morbidade da doença de Chagas. II - Estudos seccionais em quatro áreas de campo no Brasil. Memórias do Instituto Oswaldo Cruz 79: 101-124, 1984.

15. Coura JR, Anunziato N, Willcox HPF. Morbidade da doença de Chagas. I - Estudo de casos procedentes de vários estados do Brasil, observados no Rio de Janeiro. Memórias do Instituto Oswaldo Cruz 79 (supl): 107-112, 1983.

16. Coura JR, Borges-Pereira J, Araújo RM. Morbidity and regional variation in Chagas disease in Brazil. Memórias do Instituto Oswaldo Cruz 94 (supl II): 26-27, 1999.

17. Devera R, Illarramendi X, Santos N, Bóia MN, Borges-Pereira J, Coura JR. Chagas disease in Pains and Iguatama cities, State of Minas Gerais, Brazil. in: Resumos do Simpósio Internacional sobre avanços do conhecimento da doença de Chagas 90 anos após a sua descoberta, Rio de Janeiro, p. 64-65, 1999.

18. Fernandes O, Souto P, Castro JA, Borges-Pereira J, Carrara NF, Junqueira ACV, Naiff RD, Barrett TV, Degrave W, Zingales B, Campbell DA, Coura JR. Brazilian isolates of Trypanosoma cruzi from humans and triatomines classified into two lineages using mini-exon and ribosomal RNA sequences. American Journal of Tropical Medicine and Hygiene 58: 807-811, 1998.

19. Figueiredo PZ, Correia-Lima FG, Portella-Nunes JN. Doença de Chagas: primeiros casos autóctones no estado do Piauí. Revista da Sociedade Brasileira de Medicina Tropical 9: 105-107, 1975.

20. Goldbaum M. Doença de Chagas e trabalho em área urbana. Dissertação de Mestrado. Faculdade de Medicina da Universidade de São Paulo, SP, 1975.

21. Junqueira ACV, Chiari E, Wincker P. Comparison of the polymerase chain reaction with two classical parasitological methods for the diagnosis of Chagas disease in an endemic region of north-eastern Brazil. Transaction of the Royal Society of Tropical Medicine and Hygiene 90: 129-132, 1996.

22. Macedo V, Prata A, Silva GR, Castilho E. Prevalência de alterações eletrocardiográficas em chagásicos. (Informações preliminares sobre o inquérito eletrocardiográfico nacional). Arquivos Brasileiros de Cardiologia 38:261-264, 1982.

23. Neiva A, Penna B. Viagem científica pelo norte da Bahia, sudoeste de Pernambuco, sul do Piauí e de norte a sul de Goiás. Memórias do Instituto Oswaldo Cruz 8: 74-224, 1916.

24. Ramos Jr NA. Epidemiologia da doença de Chagas no Município de João Costa, Piauí. Dissertação de Mestrado, Faculdade de Medicina da Universidade Federal do Rio de Janeiro, RJ, 2001.

25. Sheps MC. An examination of some methods of comparing several rates of proportions. Biometrics 15: 87-97, 1959.

26. Silveira AC, Feitosa VR, Borges R. Distribuição de triatomíneos capturados no ambiente domiciliar, no período 1975/83, Brasil. Revista Brasileira de Malariologia e Doenças Tropicais 36:15-312, 1984.

27. Silveira AC, Vinhaes MC. Doença de Chagas: aspectos epidemiológicos e de controle. Revista da Sociedade Brasileira de Medicina Tropical 31 (supl II): 15-60, 1998.

28. Wincker P, Britto C, Borges-Pereira J, Cardoso MA, Oelemann $\mathrm{W}$, Morel CM. Use of a simplified polymerase chain reaction procedure to detect Trypanosoma cruzi in blood samples from chronic chagasic patients in a rural endemic area. American Journal of Tropical Medicine and Hygiene 51: 771-777, 1994. 